\title{
O LÚDICO NO PROCESSO DE ALFABETIZAÇÃO: POSSIBILIDADES PARA O DESENVOLVIMENTO GLOBAL DA CRIANÇA
}

\author{
Leia Regina Thome da Silva ${ }^{1}$ \\ Cleonice Alves Pereira Barroso ${ }^{2}$ \\ Joelma Adileu Pereira de Oliveira ${ }^{3}$ \\ Maria Jose de Oliveira ${ }^{4}$ \\ Suzi Satico Shiroiwa ${ }^{5}$
}

RESUMO: O presente trabalho teve por objetivo analisar a importância do lúdico no processo de alfabetização nos anos iniciais do ensino fundamental, pois sabe-se que essa etapa da educação requer a adoção de medidas para construir bases sólidas, visando o desenvolvimento global da criança. Para alcançar tal objetivo, o trabalho foi desenvolvido por meio de pesquisa bibliográfica de cunho qualitativo, realizada na consulta às publicações de referência na literatura da área. Buscou compreender como o lúdico pode auxiliar no desenvolvimento das capacidades física, social, motora, afetiva, emocional e cognitiva, além de contribuir no desenvolvimento e aquisição da leitura e escrita em um contexto que traz prazer e satisfação para as crianças. Priorizou-se a aprendizagem significativa, que valoriza os aspectos destacados acima, o contexto social e as experiências prévias da criança. Ressaltou-se a necessidade dos professores conhecerem os diversos fatores que contribuem com o desenvolvimento e aquisição do conhecimento infantil para auxiliá-los da forma mais adequada no processo de ensino-aprendizagem. Assim, compreende-se que o aluno deve ser tratado de forma singular com empatia, considerando sua emoção, seus interesses, tempo e ritmo, atitudes fundamentais que fazem a criança se sentir segura e se entregar de forma ativa e reflexiva ao objeto de conhecimento.

Palavras-chave: Alfabetização. Lúdico. Aprendizagem significativa.

ABSTRACT: This study aimed to analyze the importance of play in the literacy process in the early years of elementary school, as it is known that this stage of education requires the adoption of measures to build solid foundations, aiming at the child's overall development. To achieve this objective, the work was developed through bibliographic research of a qualitative nature, carried out in consultation with reference publications in the area's literature. It sought to understand how playfulness can help in the development of physical, social, motor, affective, emotional and cognitive abilities, in addition to contributing to the development and acquisition of reading and writing in a context that brings pleasure and satisfaction to children. Meaningful learning was prioritized, which values the aspects

'Graduação em Pedagogia - Centro Universitário São Camilo. Pós-graduação - Análises clínicas -

Universidade Nove de Julho. Licenciatura - Biologia - Universidade de Franca. Graduação - Bacharelado em

Ciências Biológicas - Universidade Nove de Julho. E-mail: leias.regina@hotmail.com

${ }^{2}$ Graduação - Pedagogia - Centro Universitário São Camilo. Atua no magistério há 26 anos.

${ }^{3}$ Graduação - Pedagogia - Centro Universitário São Camilo

${ }_{4}^{4}$ Graduação - Pedagogia - Centro Universitário São Camilo

5 Graduação - Pedagogia - Centro Universitário São Camilo.

Administração de empresas conclusão em 1993 na instituição FECAP- Fundação Escola de Comércio Álvares Penteado. 
highlighted above, the social context and the child's previous experiences. The need for teachers to know the various factors that contribute to the development and acquisition of children's knowledge to assist them in the most appropriate way in the teaching-learning process was highlighted. Thus, it is understood that the student must be treated in a unique way with empathy, considering their emotion, interests, time and rhythm, fundamental attitudes that make the child feel safe and actively and reflectively surrender to the object of knowledge.

KeyWords: Literacy. Ludic. Meaningful learning.

\section{INTRODUÇÃO}

No Brasil, o processo de alfabetização se inicia com o ingresso da criança no ensino fundamental aos seis anos de idade. Nesta fase, as crianças trazem consigo particularidades, motivações, expectativas e repertório, o que representa a elas um desafio e uma conquista, pois, "mesmo sendo dependentes dos adultos, [...] elas são pessoas ativas que sentem, pensam e interagem" (LYRA et al., 2017, p.9).

Esse momento de transição para o ensino fundamental deve ser compreendido pela escola como um período que requer a adoção de ações que contemplem acolhimento, adaptação e a socialização dos alunos. Dessa forma, torna-se necessário "valorizar situações lúdicas de aprendizagem [...] para articular com as experiências vivenciadas na Educação Infantil” (BRASIL, 2017, p. 57).

Diversos documentos oficiais asseguram a presença de atividades lúdicas na educação. Um deles foi elaborado durante Assembleia Geral das Nações Unidas em 20 de novembro de 1959, no qual líderes de diversos países aprovaram a Declaração dos Direitos da Criança, a qual foi adaptada da Declaração Universal dos Direitos Humanos. Em seu princípio VII, afirma que “a criança terá ampla oportunidade para brincar e divertir-se, visando os propósitos mesmos da sua educação; a sociedade e as autoridades públicas empenhar-se-ão em promover o gozo deste direito" (BIBLIOTECA VIRTUAL DOS DIREITOS HUMANOS, s.d., n.p.).

No Brasil, a Constituição Federal de 1988 (BRASIL, 1988), constitui um marco na educação nacional, por garantir que todos os cidadãos residentes neste país tenham permanência e acesso à educação, independente de gênero, classe social ou etnia. A presença do lúdico consta em seu sexto artigo assegurando que "são direitos sociais a educação, a saúde, a alimentação, o trabalho, a moradia, o transporte, o lazer, a segurança, a previdência 
social, a proteção à maternidade e à infância, a assistência aos desamparados, na forma desta Constituição" (BRASIL, 1988, n.p.).

O Estatuto da Criança e do Adolescente - ECA (BRASIL, 1990), foi uma lei inovadora ao inserir entre os direitos da criança e adolescente, o dever de toda família, estado e sociedade em "assegurar com absoluta prioridade, a efetivação dos direitos referentes à vida, à saúde, à alimentação, à educação, ao esporte, ao lazer, à profissionalização, à cultura, à dignidade, ao respeito, à liberdade e à convivência familiar e comunitária”. Em seu artigo I6, inciso IV, o ECA estabeleceu que o direito à liberdade das crianças e adolescentes compreende os seguintes aspectos: "brincar, praticar esportes e divertir-se". O artigo 59 determina que "os municípios, com apoio dos estados e da União, estimularão e facilitarão a destinação de recursos e espaços, para programações culturais, esportivas e de lazer voltadas para a infância e a Juventude" (BRASIL, 1990, n.p.).

Nesse contexto de mudanças, o ingresso de crianças no ensino fundamental foi alterado para seis anos de idade por meio da Lei no 1 I.II4/2005. No ano seguinte a Lei no II.274/2006 ampliou o ensino fundamental para nove anos de duração (BRASIL, 2005; 2006).

A explicação pelo início da alfabetização aos seis anos de idade se encontra no projeto de lei no 5.609/2013 com a seguinte alegação: "criança entre os cinco e seis anos de idade vive uma fase receptiva à aprendizagem com condições de dominar e usar a linguagem, essa fase precisa ser aproveitada para não comprometer o processo de alfabetização" (BRASIL, 2013, p.I4). O referido projeto de lei também recomenda que o processo de alfabetização seja realizado com a utilização do lúdico, conforme segue: "garantir à criança, a partir dos seis anos de idade, a aquisição da alfabetização e letramento na perspectiva da ludicidade e do seu desenvolvimento global" (BRASIL, 2013, p.13).

Posteriormente, o Plano Nacional de Educação (BRASIL, 2014), conduzido pelo Pacto Nacional pela Alfabetização na Idade Certa (PNAIC), fez a seguinte recomendação: "alfabetizar todas as crianças, no máximo, até o final do terceiro ano do ensino fundamental" (BRASIL, 2014, p. 85).

Diversos autores defendem os benefícios do lúdico na educação, assim, Kishimoto (1993) defende que o jogo, o brinquedo e as brincadeiras acabam sendo termos que se misturam e por alguns momentos se confundem. São atividades que contribuem para o desenvolvimento da criatividade da criança, tanto na criação como também na execução, 
são importantes, pois envolvem regras como ocupação do espaço e a percepção do lugar. Envolve também a estruturação de regras que permitem diferenciar a estrutura de cada modalidade de jogo.

Segundo a autora, essas regras têm função de construir e desenvolver uma convivência entre as crianças, possibilitando assim, um convívio mais social e democrático enquanto manifestação espontânea da cultura popular. Os jogos e brincadeiras têm a função de perpetuar a cultura infantil e desenvolver formas de convivência social.

Kishimoto (2003, p. 36) acrescenta que "o uso do brinquedo e do jogo educativo com fins pedagógicos, remete-nos para a relevância desse instrumento para situações de ensino-aprendizagem e de desenvolvimento infantil”.

O jogo como promotor de aprendizagem e do desenvolvimento passa a ser considerado nas práticas escolares como importante aliado para o ensino, já que coloca o aluno diante de situações lúdicas como o jogo pode ser uma boa estratégia para aproximá-los dos conteúdos culturais a serem vinculados na escola (1994, p. 13).

Além de constituir um ótimo recurso pedagógico no processo de ensinoaprendizagem, o lúdico educativo auxilia a criança no seu desenvolvimento pessoal em diversos aspectos, e segundo Lyra et al. (2017), contemplam os aspectos afetivo, intelectual, motor, social e neurológico.

Lyra et al. (2017) esclarecem que as brincadeiras ativam sistemas cerebrais complexos, que contribuem com o amadurecimento e transformação do cérebro da criança. Para que esse desenvolvimento ocorra de modo saudável é necessário promover situações favoráveis no ambiente familiar e escolar, que proporcionem experiências desafiadoras a favor do desenvolvimento da criança.

Embora nosso cérebro siga uma ordem biológica de desenvolvimento, quanto mais rico for o ambiente, as brincadeiras e as interações com as pessoas à sua volta, mais a criança se sentirá motivada e segura para explorar novas situações e desafios e, dessa forma, poderá criar novas oportunidades de crescimento e desenvolvimento. Conseqüentemente, auxiliará no desenvolvimento da linguagem, na construção de sua personalidade e na consciência dos valores da vida, além de se desenvolver emocionalmente. Para as autoras, a escola contribui no desenvolvimento de sua inteligência, na capacidade de resolver problemas, de se relacionar, e na auto-estima (LYRA et al., 2017). 
$\mathrm{Na}$ alfabetização, o lúdico possibilita que as crianças compreendam o sistema de escrita de forma divertida, e sem a necessidade de realizar treinos cansativos que não possuem o menor significado para elas. Brincando, as crianças se aprofundam nos conhecimentos relacionados aos princípios e funcionamento da escrita e do sistema alfabético, desenvolvem suas habilidades sociais ao compartilharem seus conhecimentos com os colegas, tendo a possibilidade de participar de forma ativa no desenvolvimento da linguagem em um contexto que lhe proporciona o deleite ao explorar textos e palavras (CENTRO DE ESTUdOS EM ALFABETIZAÇÃO E LINGUAGEM, 2009).

O lúdico também estimula a motivação por colocar a criança em situações desafiadoras, que a faz sentir necessidade de buscar mais conhecimento e superar obstáculos. Dessa forma, a linguagem verbal se aperfeiçoa simultaneamente com o desenvolvimento de suas habilidades cognitiva, sensorial, motora, social e afetiva, promovendo assim, sua autodescoberta e a integração da criança com o meio (ROSA, 2003).

Diante do exposto este trabalho se justifica, pois, verifica-se que a importância do lúdico na alfabetização representa uma forma privilegiada de desenvolvimento, aprendizagem e interações. Sendo assim, o objetivo dessa pesquisa é discutir a importância de utilizar estratégias lúdicas no processo de alfabetização de alunos dos anos iniciais do Ensino Fundamental. A metodologia de pesquisa utilizada é a pesquisa bibliográfica de cunho qualitativo, realizada na consulta às publicações de referência na literatura da área.

O trabalho se inicia discutindo a relação da criança com o lúdico, incluindo seu desenvolvimento pessoal e cerebral promovido pela alfabetização e atividades lúdicas. Destaca-se também a importância do afeto e da emoção para conseguir a participação total da criança na construção de seu conhecimento. Na segunda seção, aborda-se a importância do lúdico no processo de alfabetização, bem como o progresso da linguagem oral e a escrita. Apresentam-se também informações sobre a aprendizagem significativa, por compreender que ela se encaixa aos objetivos propostos. A terceira seção apresenta os conceitos e as classificações de jogo, brinquedo, brincadeiras e a importância deles na aquisição do conhecimento, no desenvolvimento do aluno e nas diversas interações, na sequencia há informações relacionadas às crianças que merecem ser consideradas por educadores. No final da referida seção, discute-se a função do professor na relação entre aluno lúdico e 
alfabetização. Por fim, apresenta-se as considerações finais, destacando-se entre outros aspectos os benefícios do lúdico no desenvolvimento global da criança.

\section{DESENVOLVIMENTO}

\section{I A relação da criança com o lúdico}

$\mathrm{Na}$ tentativa de entender porque as crianças apresentam diferentes respostas mediante as brincadeiras, buscou-se por respostas de alguns autores. Neste sentido, Rosa (2003) esclarece que por sua natureza inquieta e criativa, as crianças sentem a necessidade de correr, pular e jogar como forma de pensar, descobrir, experimentar, analisar, comparar, criar, compreender e sentir.

O lúdico compreende parte do desenvolvimento da criança e elas possuem várias formas de brincar, sozinha ou em grupo. Quando pequena ela brinca com duas ou três crianças no máximo. A explicação é que quando pequena, seu mundo particular é limitado e por isso ela não possui habilidades necessárias para brincar com várias crianças ao mesmo tempo, sendo necessário inclusive a presença da mãe, elas se sentem mais seguras com a proximidade de seus pais (ROSA, 2003).

O desenvolvimento do ser humano, e principalmente da criança, depende, entre outros fatores, de sua motivação ao explorar o meio em que vive. Quando as crianças brincam, elas buscam mais conhecimento e situações que possibilitam a obtenção de novos conceitos e interação com o outro. Também são motivadas a usar sua inteligência para superar obstáculos, jogar melhor e obter vitória. Essa motivação contribui para o desenvolvimento psicomotor, possibilita a autodescoberta, a assimilação e a sociabilização (ROSA, 2003).

Ao brincar, a criança desenvolve seu mundo particular traduzindo o real para o imaginário, construindo, comparando e desenhando. Essa capacidade imaginativa da criança é um processo psicológico especificamente humano que se realiza de forma consciente (ROSA, 2003). Surge com o desenvolvimento da linguagem, quando ela possui em torno de dois a três anos e começa a expressar seus sonhos, interpretar os objetos e acontecimentos. Sendo que, aos três anos sua imaginação é repleta de animismo, aos cinco ou seis anos ela agrega componentes da sua realidade (KISHIMOTO, 2003).

Sua capacidade imaginativa atravessa fronteiras e possibilita que se faça inúmeras representações paralelas com a realidade, permitindo assim, que a criança conheça 
suas capacidades e habilidades ao vivenciar situações observadas no seu cotidiano. Desse modo, conforme ela brinca, ela cria, imagina e se desenvolve. Suas necessidades (cognitivas, físicas, sociais, motoras, afetivas etc.) vão sendo preenchidas e se alterando conforme a idade (ROSA, 2003).

Outra característica peculiar da criança é a repetição, elas repetem diversas vezes tudo o que lhes proporciona prazer, geralmente aquilo que acabou de aprender, e toda ação que se repete, confere coordenação, importante para o desenvolvimento da criança (ROSA, 2003). Possui importante contribuição na educação, uma vez que essa atitude possibilita à criança degustar sua curiosidade e elaborar novas experiências. Assim, a cada brincadeira, a criança se sentirá mais segura e irá adquirir mais conhecimento (BEMVENUTI 2006).

\section{I.I $\mathrm{O}$ desenvolvimento pessoal e suas interligações}

O desenvolvimento infantil compreende um processo em constante mudança que ocorrem ao longo da vida de maneira ordenada envolvendo o desenvolvimento cerebral, as estruturas físicas, neurológicas, o pensamento, as emoções, a sociabilização e demais comportamentos (LYRA et al., 2017).

As referidas autoras explicam que esse desenvolvimento é um sistema "aberto", pois sofre influência do ambiente de convívio e das relações que se estabelecem na vida da criança. Ao mesmo tempo, é um sistema "dinâmico", já que está em constante mudança, essas mudanças envolvem as capacidades física, cognitiva, social e afetiva que se desenvolvem interligadas com as experiências adquiridas convívio social.

Um dos aspectos relacionado à mudança é nomeado por Lyra et al. (2017) como “mudanças universais”, estão relacionadas ao desenvolvimento do organismo com relação à capacidade de andar, falar e ficar de pé, e ocorre em todas as crianças. Nesse desenvolvimento não há influência da vida cultural da criança.

Outro aspecto relacionado à mudança da criança é nomeado pelas autoras, como "mudanças individuais", trata-se da característica peculiar de cada pessoa tais como, o desenvolvimento da personalidade, formação de conceitos e desenvolvimento de diversas capacidades cognitivas. Essas características são profundamente influenciadas pelo contexto social da criança. 
Lyra et al. (2017) esclarecem que crescimento é diferente de desenvolvimento. Com relação ao crescimento da criança, as autoras explicam que se trata do crescimento corporal, está relacionado ao processo biológico que ocorre naturalmente em todo ser humano devido ao aumento e desenvolvimento das células. Esse crescimento se reflete na obtenção de peso e evolução da altura.

No que diz respeito ao desenvolvimento da criança, Lyra et al. (2017) elucidam que está relacionado à obtenção de novas habilidades e capacidade de realizar atividades complexas. Durante esse processo, alguns fatores externos como, ambientais, cuidado e experiências, são fundamentais para desenvolver as habilidades relacionadas.

Nesse processo está incluído o desenvolvimento cerebral (neurodesenvolvimento), trata-se de um processo que ocorre ao longo da vida, porém, com mais intensidade na infância e adolescência, ele sofre influência direta do contexto que a criança está inserida. O cérebro do bebê é imaturo e plástico, ou seja, não ocupa toda a caixa craniana, seu desenvolvimento dependerá das experiências que a criança tiver durante o desenvolvimento. Entre zero e três anos o cérebro se desenvolve com mais intensidade, devido ao amadurecimento e conexões entre os neurônios. É o período considerado como sensível para o desenvolvimento de competências sensoriais, habilidades sociais, afetivas, motoras, desenvolvimento da linguagem, pensamento e funções executivas (LYRA et al., 2017).

Para que esse neurodesenvolvimento ocorra de modo saudável, é necessário a promoção de um ambiente afetivo, acolhedor e amoroso, tanto na escola, como na família. Bem como exposição à experiências ricas e promotoras de desenvolvimento (brincadeiras, canções, desenhos, conversas). Insere-se nesse contexto a boa qualidade do sono $\mathrm{e}$ alimentação, que são imprescindíveis para o desenvolvimento e amadurecimento cerebral (LYRA et al., 2017)

Embora nosso cérebro siga uma ordem biológica de desenvolvimento ele é fortemente influenciado pelas vivências e experiências de cada pessoa. Esse processo ocorre devido à "plasticidade cerebral", que é a capacidade que nosso cérebro possui de fazer e desfazer as conexões entre os neurônios. Assim quanto mais rico for o ambiente e mais diversas forem as atividades lúdicas, maior será a possibilidade que a criança terá para 
desenvolver sua inteligência, sua autoestima e demais aspectos do seu desenvolvimento (LYRA et a., 2017).

As experiências adquiridas na escola desempenham grande influência no desenvolvimento cerebral da criança. Isso reflete na evolução de diversas habilidades como inteligência, autoconhecimento, sociabilização e capacidade de resolver problemas (LYRA et al., 2017).

\subsubsection{Afeto, emoções e suas interligações}

A dimensão afetiva é fundamental na educação, pois para que a criança adquira seu autoconhecimento, é necessária relação de afeto entre aluno e professor. Essa é uma característica do ser humano, ele necessita ser amado, acolhido, valorizado e ouvido. A afetividade auxilia na capacidade de pensar, analisar os problemas de sua vida, fazer planos, executar ações com prazer e competência (ROSA, 2003).

O afeto é uma relação que se estabelece a partir das experiências que ocorrem no convívio da criança. Por meio dessas relações, as crianças constroem o conceito sobre seu ambiente e sobre a pessoa na sua relação de afeto. Esse ambiente, tanto pode ser prazeroso ou ameaçador. É a partir dele que a criança construirá seu autoconceito e sua autoestima (LYRA et al., 2017).

Existem diferentes situações de afeto que irão contribuir para a construção das experiências e conceitos da criança. Uma delas se chama "afeto seguro", nessa relação a pessoa responsável pelo afeto promove proteção e segurança, possibilitando para a criança o desenvolvimento das habilidades de exploração, autonomia, e a capacidade de enfrentar as dificuldades e desafios (LYRA et al., 2017).

Outra relação é o afeto "inseguro ambivalente". A pessoa responsável pelo afeto não serve como uma base segura, por não permitir que haja confiança e nem que a criança adquira autonomia. Essa é uma característica de educação superprotetora (LYRA et al., 2017).

Há também a relação de afeto "inseguro evitante”. Nesse caso o responsável pelo afeto não constitui um exemplo para a criança desenvolver suas habilidades, pois não transmite afeto e nem segurança para criança. Essa relação se configura como autoritária e negligente (LYRA et al., 2017). 
As referidas autoras salientam que para as crianças se desenvolverem de forma saudável, elas precisam estabelecer relações de confiança entre seu elo de afeto. Essa figura do afeto precisa ser alguém na qual elas possam confiar e recorrer quando for necessário, alguém que as façam sentir seguras.

A emoção é a manifestação de algum acontecimento importante na vida da pessoa. Na educação, ela precisa ser considerada e desenvolvida, pois contribui para o bom desempenho na aprendizagem, minimiza problemas relacionados à disciplina e torna as pessoas mais capazes de viver em sociedade e alcançar sua realização social. Ela expressa nossos sentimentos e constituem um importante mecanismo de expressão entre as pessoas, pois, podemos perceber as emoções das pessoas que estão ao nosso redor. E da mesma forma que percebemos as emoções de outras pessoas, podemos nos comunicar (CONSENZA; GUERRA, 20II).

Consenza e Guerra (20II) acrescentam que ao longo da vida aprendemos a controlar nossas emoções de forma que elas sejam aceitas socialmente. Aprendemos também, a refletir sobre os comportamentos que poderíamos provocar como conseqüência de nossa emoção. Essa capacidade é desenvolvida durante o processo de educação nos momentos que se orienta uma criança a não brigar, não bater no colega, e resolver conflitos por meio de conversa.

A emoção produz motivação, trata-se de um processo que exprime informações advindas de processos internos (fome, dor etc.), e de processos externos (oportunidade e ameaça), também define o comportamento a ser expresso. A maioria dos comportamentos advindos por motivação são aprendidos e realizados para uma finalidade. Nossas motivações nos fazem repetir diversas vezes ações que possibilitaram recompensa ou procurar situações semelhantes que tragam a mesma satisfação. Portanto, a motivação e extremamente importante na aprendizagem (CONSENZA; GUERRA, 20II).

O desenvolvimento emocional do indivíduo se inicia no nascimento e sofre diversos processos no decorrer das evoluções nas demais fases da vida, ele é bastante complexo e nunca acaba (PANTANO; ROCCA, 2015). Todos esses processos têm origem no cérebro e envolvem respostas periféricas que podem facilmente ser percebidas externamente (estado de alerta aumentado, desassossego, dilatação da pupila, sudorese, lacrimejamento, alteração na expressão facial etc.). Envolve ainda, modificações corporais 
internas que somente o próprio sujeito percebe como "coração disparado", "frio no estomago" e "nó na garganta” (CONSENZA; GUERRA, 20II).

Todas as alterações que ocorrem no indivíduo como decorrência da emoção estão atreladas a capacidade afetiva (desanimo, irritação, euforia etc.). Conseguimos também identificar a emoção que estamos sentindo (amor, medo, ódio, ciúme etc.). Podemos ainda, controlar nossas emoções (CONSENZA; GUERRA, 20II).

Porém, nem sempre as emoções trazem resultados positivos, pois a ansiedade e estresse em excesso podem ter efeito contrário na aprendizagem e prejudicar o desenvolvimento do aluno. $O$ estresse ocorre quando a pessoa se sente desamparada, ou quando não consegue superar suas dificuldades. Algumas situações no cotidiano também provocam estresse (chacotas, ameaças). Outras, podem vir do próprio professor tais como, excessos na disciplina e excessos no processo de avaliação (CONSENZA; GUERRA, 20II).

Consenza e Guerra (2011) ressaltam que professores devem se atentar, igualmente, para suas próprias emoções. A linguagem emocional é ao mesmo tempo uma linguagem corporal e verbal. Assim, nossas emoções interferem naquilo que falamos e transmitimos e muitas vezes não percebemos. Esses fatores podem fazer com que a mensagem transmitida tenha um efeito bem diferente ao desejado.

Por tais motivos, a emoção possui grande importância na educação, dessa forma, a escola deve possibilitar um contexto com estratégia que mobilizem emoções positivas (entusiasmo, curiosidade, envolvimento, desafio). E evitem situações que produzam emoções negativas (ansiedade, apatia, medo, frustação). (CONSENZA; GUERRA, 20II).

\subsection{Alfabetização e o lúdico: uma relação necessária}

A alfabetização é um processo complexo que envolve a aquisição da leitura, escrita e regras do sistema silábico que se desenvolvem a partir da linguagem oral que a criança traz consigo (NICOLAU; MAURO, 1986). Envolve também o emprego de diversos sinais gráficos como: ponto, traços, linha e demais sinais. São processos que implicam no desenvolvimento das habilidades cognitivas, físicas e sociais (ROSA, 2003).

Não é uma tarefa fácil para o educador. Entretanto, esse processo pode ser facilitado com a inserção de atividades lúdicas que além de ser uma forma divertida e 
agradável de aprender, promove o desenvolvimento das capacidades efetivas, emocionais, sociais, cognitivas e constitui um ótimo recurso pedagógico (ROSA, 2003).

O lúdico representa um grande auxílio na alfabetização por possibilitar que as crianças entendam o sistema de escrita sem a necessidade de se submeter a exercícios cansativos e que não fazem o menor sentido para elas. Permite que as crianças ampliem seus conhecimentos relacionados ao funcionamento da escrita, e ainda tem a vantagem, de poder compartilhar seus conhecimentos com seus colegas desenvolvendo assim, suas habilidades sociais. Também possibilita que as crianças tenham a oportunidade de participar de forma ativa e reflexiva na construção de seu conhecimento sobre o sistema silábico, e de se envolver em diversos textos e palavras de forma prazerosa num contexto que faz parte do mundo delas (CENTRO DE ESTUDOS EM ALFABETIZAÇÃO E LINGUAGEM, 2009).

Atividades lúdicas possuem diversas formas de utilização e de expressão, essa característica aliada à capacidade criativa da criança contribui para que ela consiga substituir a função ou significado de um brinquedo por outro, possibilitando assim, o desenvolvimento de sua comunicação e expressão que evolui naturalmente para o uso criativo da linguagem (NICOLAU; MAURO, 1986).

Como resultado, a escrita vai se desenvolvendo naturalmente conforme as relações e interações que surgem no espaço escolar e familiar. Ela se torna necessária quando a criança percebe a importância de sua utilização na vida pessoal, social, em situações que exigem a comunicação verbal ou quando há necessidade escrever ou se lembrar de uma mensagem escrita (ROSA, 2003).

O lúdico também tem a função de aguçar a sensibilidade da criança com relação ao seu meio, permitindo que ela adquira percepção dos objetos, sons cores e movimentos (NICOLAU; MAURO, 1986). Essa percepção sensorial tem importante contribuição no processo de alfabetização uma vez que compreendemos o mundo pelos sentidos, cheirandoo, vendo-o e ouvindo-o. Quando precisamos manifestar esses processos internos, utilizamos a linguagem verbal e a expressão motora (ROSA, 2003).

\subsubsection{O aluno no centro do processo de alfabetização}

A escola tem a responsabilidade de ensinar significativamente o conhecimento, deve conhecer e aproveitar o processo pelo qual os alunos se desenvolvem como sujeitos, 
com relação a sua forma de entender o mundo e de tomar atitudes relacionadas a seus conhecimentos, pré-requisito para o exercício da cidadania. Esse processo de aquisição e construção do conhecimento tem início no meio social e se introduz para o individual. $\mathrm{Ou}$ seja, através do contato com o seu meio de convívio, o que possibilita adquirir diversas experiências e a formação de conceitos (WEISZ et al., 2008).

Esse conhecimento adquirido do social para o individual serve de base na educação para agregar novos conceitos e facilita a construção do pensamento abstrato, atenção voluntária, comportamento, planejamento, comparações etc. Os conceitos prévios do aluno quando mediado pelo professor, permite a articulação e a incorporação de novos valores, os quais ocorrem a partir de intensos processos cognitivos no aluno. Nesse processo, a interação entre os conhecimentos novos e os prévios ocorre por uma entrega total do aluno na obtenção de novos conhecimentos. Essa aprendizagem faz com que o aluno revise seus conceitos anteriores, substituindo-os por conceitos novos e diferentes para, dessa forma, adquirir capacidades necessárias para uma educação integral, as quais serão desenvolvidas e consolidadas conforme a maturidade do aluno (WEISZ et al, 2008).

Essa proposta de educação privilegia uma alfabetização centrada na reflexão sobre a escrita com atividades de uso significativo da linguagem. Ou seja, é necessário desenvolver um trabalho pedagógico em contextos de aprendizagem, onde o uso da linguagem faz sentido para a vida do aluno e intensifiquem sua aquisição (WEISZ et al., 2008).

Para promover tais contextos, a escola precisa desenvolver um processo de alfabetização que se encaixe às necessidades do aluno, reconhecendo que eles têm o direito de obter sucesso na aprendizagem, possibilitando assim, que se desenvolvam pessoalmente e se reconheçam como sujeitos no mundo, carregando uma imagem positiva de si mesmos. É necessário também, ensinar a ler e escrever assegurando que as crianças tenham a oportunidade de se aproximar de diversos textos, sendo eles adequados ao trabalho proposto. A escola também deve planejar atividades que estimulem seus alunos, porém, considerando o real conhecimento deles (WEISZ et al., 2008).

Ainda de acordo com as autoras, o professor deve utilizar seus conhecimentos sobre os processos de desenvolvimento e aquisição da leitura e escrita, a fim de elaborar atividades adequadas ao desenvolvimento dos alunos. Ele também precisa se posicionar 
como parceiro dos alunos durante o processo de leitura, escrita e atividades relacionadas, e dessa forma, se estabelecer como um modelo de referência para os alunos.

Weisz et al. (2008) esclarecem que essa proposta de alfabetização contraria os procedimentos tradicionais behavioristas que enfatizam a memorização de conteúdos isolados e descontextualizados. Assim, não adianta memorizar conteúdos como se fosse uma informação simples, pois certos conceitos se adquirem vivenciando situações que representam valores na vida. Da mesma forma que não basta memorizar infinitas famílias silábicas para compreender os princípios do sistema alfabético, uma vez que a alfabetização é um processo complexo que requer assimilação e compreensão de regras do sistema escrito e alfabético, para compreender tais regras, é necessário que o aluno aprenda a refletir sobre suas propriedades e funcionamento por meio de práticas.

Para Weisz et al. (2008), não basta memorizar informações para interpretar, redigir e refletir textos, é preciso praticá-los, a fim de adquirir habilidade para realizá-los. A aquisição do conhecimento ocorre com o uso, portanto, aprender a ler e escrever lendo e escrevendo, requer uma serie de análises e reflexão sobre a escrita. É um objeto do conhecimento que requer do aprendiz um elevado grau de formação de conceitos, seja ele criança ou adulto. Assim, uma informação se torna sólida quando é vivenciada em situações que representam importância na vida do aluno.

As autoras explicam que para ler textos quando ainda não se tem noção da leitura, é preciso utilizar o conhecimento prévio que o aluno possui sobre o valor sonoro das letras e a informação parcial que ele tem sobre o texto, possibilitando dessa forma, que se faça suposições acerca daquilo que pode estar escrito. Para interpretar a própria escrita é necessário que o aluno entenda e consiga explicar o porquê de tais letras, o porquê da quantidade de letras, e qual a semelhança e diferença entre elas.

Enfim, não é nada fácil alfabetizar lendo e escrevendo, entretanto, alfabetizar por meio da memorização é muito mais difícil. Além do mais, esta última, não capacita o aluno para fazer o uso da linguagem em diferentes situações comunicativas (WEISZ et al., 2008).

Partindo desse conceito, principalmente quando se diz que a educação deve ser realizada em diferentes contextos, entende-se que a educação significativa abre as portas para o lúdico. Assim, Rosa (2003) conceitua que é necessário resgatar o direito do aluno para 
uma educação que considere seu modo de pensar, permitindo que se desenvolva nas linguagens do jogo, do desenho, e da música como meio expressivo da leitura e escrita.

Rosa (2003) defende ainda que o desenvolvimento da leitura e escrita é uma inclinação natural da criança, e quando facilitado com a inserção de atividades lúdicas, promove maior compreensão desses dois conceitos. Assim sendo, é importante dar oportunidade para que o aluno revele seu conhecimento por meio das brincadeiras, propiciando espaços e situações que articulem condições afetivas, emocionais, sociais e cognitivas aos seus conteúdos da linguagem e escrita. Podendo inclusive, adaptar as brincadeiras, jogos, cantigas, e histórias ao contexto dos alunos e conseqüentemente, facilitar uma interação física e emocional entre professor e aluno.

Segundo Rosa (2003), as crianças precisam perceber que por meio das brincadeiras elas desenvolvem sua linguagem oral e escrita. Contudo, sem que isso se torne uma regra, ela deve ocorrer de forma interligada durante as brincadeiras sugeridas pelo professor e em cada exposição feita pelas crianças durante os jogos. Dessa forma, são motivadas a aprender de maneira espontânea, sem cobranças e no seu próprio mundo infantil.

Por meio da teoria e prática, professor e aluno aprendem juntos, testando limites, procurando alternativas, questionando valores, métodos e tendências. O educador deve resgatar com prazer e alegria a importância do brincar, transformando o lúdico sua prática pedagógica no cotidiano (ROSA, 2003).

A autora esclarece que as brincadeiras também possibilitam a convivência social por meio das interações que se estabelecem, assim, a criança aprende a respeitar o próximo e os conceitos diferentes do seu. Possibilita à criança construir seu mundo particular por meio das interações que se estabelecem entre as brincadeiras, assim ela compara, explora e constrói seu conhecimento.

\subsubsection{Linguagem oral e escrita}

As crianças ingressam no ensino fundamental se comunicando oralmente, essa habilidade ela desenvolve naturalmente no seu meio social e sem a necessidade de uma explicação, regras ou treinos. Essa faculdade humana está relacionada às funções cognitivas 
e aos estímulos externos promovidos pelo ambiente ao qual a criança está exposta (NICOLAU; MAURO, 1986).

O convívio com a fala de pessoas que estão próximas (familiares, amigos, professores, meios de comunicação etc.), e o meio ambiente propício (canto, escuta de música, brincadeiras etc.) fornecem condições para que essa capacidade se desenvolva e se torne sólida. Portanto, o desenvolvimento da linguagem oral envolve uma relação e verbalização, que são estabelecidas entre pessoas que buscam a comunicação (ROSA, 2003).

Segundo a autora, todo falante nativo usa a língua conforme as regras próprias do seu contexto social, portanto, ela representa aspectos de sua comunidade. Assim, a escola deve considerar a fala, pois ela tem a responsabilidade de pesquisar e explicar como a língua funciona. Enfim, a língua sobrevive e se concretiza por meio da fala.

A linguagem humana tem função comunicativa, porém, nem sempre a comunicação é a função mais importante no uso da linguagem. Visto que ela possui diversas funções além de transmitir informação e comunicação. Ela pode ser usada, por exemplo, para exprimir um sentimento, uma exclamação ou uma ameaça (ROSA, 2003).

A linguagem oral é a base para alcançar a leitura e escrita, portanto, assume importância considerável na alfabetização, por funcionar como um meio de comunicação e ao mesmo tempo um objeto de aprendizagem onde a interação entre professor e aluno; aluno e aluno; aluno e sua realidade; aluno e conhecimento a ser adquirido renovam e constroem processo educativo se ajustando às necessidades e características de cada criança (NICOLAU; MAURO, 1986).

Nas diversas situações de fala, as crianças vão percebendo a freqüência das estruturas que compõem a linguagem oral e dessa forma utilizam todos os recursos que conhecem (histórias e palavras que fazem parte da comunicação de sua família etc.) para criar suas próprias palavras e expressões na tentativa de adquirir o conhecimento da linguagem (ROSA, 2003).

À medida que a criança consegue falar com mais precisão aquilo que deseja, a fala se torna importante meio de comunicação. O desenvolvimento da fala e da capacidade simbólica amplia as habilidades intelectuais, porém na visão da criança, a fala está condicionada ao seu mundo particular (ROSA, 2003). 
No trabalho com a linguagem oral, alguns aspectos merecem destaque. Um deles consiste em promover situações de comunicação onde a criança consiga perceber a diferença lingüística no seu meio de convívio. Assim, contar fatos que ocorrem no cotidiano entre familiares e colegas constitui uma ótima oportunidade de comunicação. Também deve promover situações de nas quais a criança consiga relatar suas experiências e observações com situações em que ela possa descrever o que sentiu, e expressar sua opinião sobre o assunto (NICOLAU; MAURO, I986).

A poesia quando utilizada de forma lúdica recorre à imaginação, emoção e expressão. A combinação da poesia com a música é uma excelente oportunidade de leitura. A música envolve o desenvolvimento rítmico, a imaginação, movimentação corporal e a discriminação dos sons e consequentemente a expressão verbal (NICOLAU; MAURO, 1986).

Conforme Nicolau e Mauro (1986), a narrativa também é uma ótima oportunidade da comunicação, narrar descrevendo figuras e cenas, possibilita a observação e comparação de várias características (tamanho, cor, forma, volume entre outros), e consequentemente desenvolve a leitura.

Para as autoras a dramatização é uma atividade que permite várias formas de expressão (musical, corporal, plástica etc.). A utilização de jogos dramáticos com cenas curtas e situações da vida das crianças, situações extraídas do imaginário delas, extraídas do folclore, ou personagens de desenhos infantis, possibilita o desenvolvimento de vários sentidos, incluindo a linguagem.

A escrita pode ser definida como um conjunto de sinais gráficos que representa os sons produzidos durante a fala, assim, ela assegura a sobrevivência da linguagem falada e se constitui uma prova da existência dela. Ela não é um produto escolar, e sim um objeto cultural desenvolvido pela humanidade (ROSA, 2003).

Para a criança, a escrita representa um objeto com regras específicas que funcionam de acordo com a importância e significado elaborado por ela em diferentes formas. Fazem parte de sua escrita, pictogramas, símbolos, números, letras ou até mesmo a língua falada (ROSA, 2003).

A autora explica que criança começa a perceber e questionar acerca da escrita desde que começa a interagir com objetos de leitura pela primeira vez. Através das diversas 
interações sociais, e principalmente, por meio das brincadeiras que representam diversas hipóteses sobre a escrita, consequentemente a criança vai construindo seu conceito de escrita.

Estudos realizados por Ferreiro e Teberosky (1985, apud ROSA, 2003), revelam que crianças formulam hipótese observando e questionando os rabiscos, sinais e marcas com os quais elas interagem nas brincadeiras. $\mathrm{Na}$ medida em que vão progredindo, elas criam mais hipóteses, realizam prova, constroem e reconstroem. Por fim, acabam se apropriando da escrita convencional.

Segundo Rosa (2003), diferenciar escrita do desenho constitui um grande passo na construção da escrita. Exige muito questionamento, pensamento, fazer ralações e levantar hipóteses. O momento importante é quando a criança percebe que a escrita se relaciona diretamente com a fala e não com o formato do objeto. Nesse momento, ela descobre o grande mistério da escrita e começa a construir outra hipótese, a de que para cada voz emitida é produzida uma letra, essa fase é conhecida como a hipótese silábica.

Do ponto de vista cultural, o lúdico tende a inserir as crianças no processo de desenvolvimento da escrita. Por meio das atividades lúdicas, a criança consegue criar situações imaginárias e se comporta como se estivesse no mundo dos adultos, consequentemente, vai ampliando seu conhecimento de escrita (ROSA, 2003).

A criatividade e capacidade imaginativa da criança possibilita que ela própria crie suas metodologias, normas e regras gramaticais. Assim, colocam suas imaginações em prática, julgando que todos entendem o que ela está tentando expressar. Essa criatividade deve ser explorada no desenvolvimento da leitura e escrita sendo possível contextualizar atividades, navegando com elas no universo da leitura por meio de teatros, jogos, dramatizações e histórias para elas assimilarem e, consequentemente, construir seu próprio modo de escrita (ROSA, 2003).

A autora esclarece que o desenvolvimento da criança está aliado à sua própria história e seu mundo cultural. Esses valores associados ao conhecimento prévio que a criança possui sobre escrita concedem inúmeras possibilidades, podendo apresentar a ela diversos estilos de textos, que trazem informações próximas à realidade dela. Músicas, histórias, poesias, receitas são ótimos recursos. 
Deve-se atentar que a expressão oral também constitui um texto. Sendo assim, atividades que proporcionam o desenvolvimento da expressão oral de forma livre, faz com que o aluno se sinta seguro no momento de desenvolver um texto escrito. Toda forma que uma criança utiliza para expressar sua escrita deve ser considerada e explorada, pois possui um significado no mundo infantil (ROSA, 2003).

\subsection{O brinquedo e o jogo como subsídios para a alfabetização}

$\mathrm{Na}$ concepção de Kishimoto (2003) o brinquedo é um objeto ou jogo que possui uma relação íntima com a criança, por não possuir regras que determinam sua manipulação e por permitir diferentes formas de utilização, possibilitando assim, que a criança lhe atribua diferentes significados.

O brinquedo permite uma representação da realidade por inserir a criança num universo de reproduções, e tudo o que existe no cotidiano da criança poderá ser representado nas brincadeiras. A possibilidade de reproduzir diversas realidades presentes no brinquedo permite a reprodução de todos os aspectos da vida social tais como: modo de pensar, valores, natureza etc. (KISHIMOTO, 2003).

A autora salienta que mesmo não sendo uma cópia idêntica da realidade por possuir características simples, delicadas e pequenas, o brinquedo permite que a criança faça várias analogias com sua realidade. O mundo imaginário presente nos desenhos animados, seriados de televisão, mundo encantado, mundo de ficção cientifica também pode ser incorporado aos brinquedos de diversas formas, mas preferencialmente no formato de bonecos como super-heróis, máquinas, monstros etc.

Em suma, o brinquedo enquanto objeto, é a base para a brincadeira, é um estimulante que possibilita à criança navegar no imaginário infantil. Essa relação peculiar que cada criança possui com o brinquedo é a brincadeira, é o lúdico atuando (KISHIMOTO, 2003).

Com relação ao jogo, Kishimoto (2003), argumenta que não é nada fácil definilo, pois, cada grupo social the atribui um significado que funciona conforme seus valores e modo de vida. Assim, diversas atividades podem ser consideradas como jogos, no entanto, cada uma delas apresenta uma característica que a distingue das demais por sua importância e seu significado no contexto social. 
Em uma definição menos abrangente, o jogo pode ser interpretado como resultado de costumes e atividades culturais que funcionam dentro de um grupo social. Sua função irá depender da linguagem utilizada naquele contexto, pois sendo a língua uma forma de expressar a realidade, ela reflete a vida social e as formas de pensar e falar de um grupo. Elas são manipuladas pelo desejo da vida cotidiana, daí a importância de respeitar o uso cotidiano e social da linguagem, eles trazem consigo interpretações da vida social (KISHIMOTO, 2003).

A autora esclarece que por ser um fato social, o jogo assume o sentido que cada sociedade lhe atribui. Dessa forma, um objeto que funciona como brinquedo numa uma sociedade, pode funcionar como um utensilio necessário para outras, ou ainda como um objeto inútil em outra sociedade. Sendo assim, cada sociedade constrói seu conceito de jogo conforme seus valores e costumes, que se manifestam através da linguagem.

O Centro de Estudos em Educação e Linguagem (2009) corrobora ao defender que o jogo pode ser um meio de conservar a história da humanidade. Por fazer parte de diferentes épocas da vida das pessoas, acaba transmitindo a influência deles na construção da personalidade e no modo de aprendizagem das pessoas.

O jogo também pode ser definido como um sistema de regras que permite identificar e diferenciar cada modalidade dele. Nesse caso, o foco consiste em obedecer às regras compartilhadas, mesmo que façam parte de um mundo imaginário. Essa estrutura de regras permite que o jogo seja utilizado com a função lúdica, assim, quando alguém joga, está respeitando as regras e ao mesmo tempo realizando uma atividade lúdica (KISHIMOTO, 2003). Sendo assim, o jogo contribui para o fortalecimento de condutas morais e sociais no desenvolvimento da criança (CENTRO DE ESTUDOS EM ALFABETIZAÇÃO E LINGUAGEM, 2009).

A brincadeira é definida por Kishimoto (2003, p.21) como "ação que a criança desempenha ao concretizar as regras do jogo e mergulhar na ação lúdica, [...] dessa forma, brinquedo e brincadeira relacionam-se diretamente com a criança". Entende-se que brincadeira é relação íntima que a criança possui com o brinquedo ao se entregar por inteiro e ingressar em um mundo imaginário.

Bemvemuti (2006) acrescenta que a manipulação de brinquedos durante as brincadeiras depende do corpo, ele está sempre atrelado à aquisição do conhecimento, a 
percepção, a interação e transformação de jogos, brinquedos e brincadeiras, que fazem parte da vida cultural. Portanto, a participação das crianças em qualquer tipo de jogo se dá pelo uso das mãos, olhos e mente. Assim, jogos brinquedos e brincadeiras estão interligados a nossa forma de pensar, sentir, perceber, conhecer, e dialogar com o nosso corpo, com o corpo do outro e com o espaço em que vivemos.

A autora esclarece ainda que nossos corpos também permitem, limitam, abrem, fecham ou expandem nossa relação com brinquedo, pessoas, e com o espaço onde brincamos. Assim, uma criança pequena terá mais dificuldade de jogar basquete, corpos mais flexíveis terão mais facilidade para brincar na cama elástica, mãos ágeis e rápidas terão mais facilidade para encaixar peças de quebra cabeça.

Contudo, não significa que nossos corpos determinam o tipo de brinquedo que nos cabe, as brincadeiras não estão obrigatoriamente limitadas às características e capacidade do corpo. Pois, cada corpo cria e estabelece diferentes relações diante dos mesmos brinquedos, jogos e brincadeiras, a explicação é que nosso corpo está interligado à nossa determinação, vontade, querer e emoção que, muitas vezes, criam condições que são limitadas por nossos corpos (BEMVEMUTI, 2006).

O brinquedo educativo é compreendido como mecanismo que ensina, educa e desenvolve de forma alegre. Quando é utilizado para fins pedagógicos têm dois objetivos: ensino-aprendizagem e desenvolvimento infantil (KISHIMOTO, 2003). Com base nas duas classificações, a autora descreve várias situações que diferenciam ensino, aprendizagem e desenvolvimento.

Sendo assim, se partirmos do princípio que a criança aprende de forma espontânea, envolvendo-se por inteiro com suas funções cognitiva, afetiva, social e corporal, verifica-se que o brinquedo desempenha grande função para o desenvolvimento dela. Assim, se o professor disponibilizar brincadeiras que possibilitem o envolvimento total da criança, o brinquedo contribuirá para o desenvolvimento e aprendizagem da criança (KISHIMOTO, 2003).

Kishimoto (2003) acrescenta que quando o educador utiliza o lúdico com a finalidade de estimular a aprendizagem, configura-se a função educativa. Neste sentido, essa situação também pode se configurar como "situações de aprendizagem", se forem mantidas condições que possibilitem a participação ativa da criança mediante a brincadeira. Utilizar 
o lúdico na educação significa utilizar uma estratégia de ensino-aprendizagem, a fim de que ela contribua para acelerar a construção do conhecimento de forma prazerosa e com a participação espontânea, ativa e motivadora da criança. Ao assumir a função educativa, o brincar de forma livre se distancia da busca por resultados. Porém, considerando que o lúdico deve proporcionar prazer e diversão, alguns aspectos precisam ser observados e considerados para reunir educação em um contexto lúdico.

A referida autora demonstra dois exemplos para diferenciar situações lúdicas e educativas. Explicamos essas situações da seguinte forma: quando criança está realizando uma atividade proposta pelo professor de forma livre, prazerosa e ao mesmo tempo aprendendo, significa que a função lúdica e educativa está presente na brincadeira. Por outro lado, se a criança prefere utilizar um brinquedo para uma função diferente daquela proposta pelo professor e fazer de conta que está construindo outro brinquedo, como por exemplo, utilizar cartas para fazer de conta que está construindo um castelo, significa que estão reunidas a função lúdica, imaginativa, criativa e habilidades necessárias para aquela brincadeira. A autora defende que "a utilização do jogo potencializa a construção do conhecimento, por contar com a motivação interna" (KISHIMOTO, 2003, p.37).

Essa é uma das características do brinquedo educativo, proporcionar diferentes situações de aprendizagem e diferentes formas de interpretação, porém, nem sempre garante ao professor que seus objetivos com relação ao conhecimento adquirido pela criança terão o mesmo resultado planejado por ele (KISHIMOTO, 2003).

Neste sentido, Rosa (2003) esclarece que o segredo para reunir educação e brincadeira consiste em adaptar a brincadeira natural e espontânea da criança em uma atividade de importância pedagógica, com isso o educador manterá sua função lúdica. Kishimoto (2003) defende a possibilidade de usar a motivação da criança para unir educação e brincadeira. Sabe-se que a motivação é um benefício que o brinquedo produz e que aguça a exploração e a busca pelo conhecimento. Neste caso, mesmo sendo um processo espontâneo por parte da criança, cabe ao professor oferecer recursos necessários para tornar a brincadeira uma situação educativa, dispondo parceiros, condições para formação de conceitos e demais situações que promovem a aprendizagem.

A brincadeira tradicional infantil está atrelada ao folclore e parte da cultura popular de um povo, trata-se daquela cultura não oficial que se desenvolve de forma oral e 
se transmite de geração em geração. Motivo pelo qual, está em constante transformação, e por fazer parte do folclore de um povo, possui características de uma brincadeira tradicional onde não se conhece a origem nem seu inventor. Por ser transmitida de forma livre e espontânea, produz formas de convivência social e mantem a função lúdica e imaginaria no universo infantil. Fazem parte dessa brincadeira a amarelinha, pião, parlendas etc. (KISHIMOTO, 2003).

A brincadeira de faz de conta, ou simbólica, de representação de papéis ou sociodramática aguçam a capacidade imaginativa da criança. Tais brincadeiras promovem a manifestação de regras estabelecidas no imaginário infantil. O imaginário infantil procede de diferentes contextos vivenciados pela criança no seu meio de convívio, entre eles a família, escola e colegas (KISHIMOTO, 2003).

Para Kishimoto (2003), a importância dessa brincadeira na educação reside na sua função simbólica, ela permite que a criança tenha a oportunidade de dar diferentes significados aos jogos e brinquedos e criar diferentes contextos com eles, consequentemente, a criança desenvolve sua racionalidade e aprende a criar símbolos. A escola deve propor um currículo com conteúdo adequado para promover uma educação lúdica com temas, materiais necessários, tempo disponível e oportunidades para interação.

A brincadeira ou jogo de construção permite que as crianças desenvolvam suas capacidades sensoriais, criativa e outras diversas habilidades. Ela também possibilita a entrada no mundo do "faz de conta", assim quando a criança está manipulando um objeto, seu mundo imaginário está agindo e transportando a criança para várias representações. Dessa forma, a construção de um objeto se transforma em histórias elaboradas no mundo imaginário da criança, e se evolui conforme o desenvolvimento da criança (KISHIMOTO, 2003).

Segundo a autora, essa brincadeira possibilita que a criança consiga expressar seus problemas quando constrói, transforma e destrói, dessa forma, ela se torna um grande subsídio para terapeutas, uma vez que conseguem diagnosticar problemas de adaptação.

Essa brincadeira também constitui um grande auxílio para educadores por permitir o desenvolvimento afetivo e emocional, bem como estimular a imaginação da criança. Essa caraterística contribui para a criança expressar seus esquemas mentais e manipular diversos objetos. A relevância dessa brincadeira na educação remete a relação 
intrínseca que existem entre fala e ação, e que muitas se revelam conflituosas na criança. É importante se atentar para as ideias da criança que estão presentes no momento que brincam, as quais terão importante contribuição na elaboração dos temas. Deve se atentar também, como o mundo real colaborou para a construção da brincadeira. (KISHIMOTO, 2003).

\subsection{O que os professores precisam saber sobre os alunos para ensiná-los}

A criança é um ser humano em desenvolvimento que sofre mudanças biológicas, psicológicas e sociais que se desenvolvem de forma interligada (ROSA, 2003). Partindo desse entendimento, e considerando que as propostas de ensino atuais têm por objetivo oferecer uma educação integral, faz-se necessário que os professores conheçam seus alunos e consigam analisar e identificar os diversos fatores que contribuem para seu desenvolvimento e aprendizagem.

Assim, Rosa (2003), conceitua que a criança é um ser social que nasce com capacidades afetivas, emocionais e cognitivas, necessitando estar sempre próxima às pessoas. Nessas interações sociais entre adultos e crianças, ela se sente mais segura para se expressar e explorar seu ambiente. Essas relações possibilitam que ela aprenda, adquira novos conceitos, amplie suas relações sociais e sua capacidade de comunicação.

Nicolau e Mauro (1986) acrescentam que as crianças são ativas e constroem seu conhecimento em interação com o ambiente, essa habilidade possibilita que cada criança ingresse no ensino fundamental apresentando diferentes capacidades cognitivas, diferentes conhecimentos e diferentes experiências de vida. A experiência que a criança possui enriquece o conteúdo no processo de alfabetização.

A psicogenética explica que o processo pelo qual se aprende a ler e escrever é o mesmo para pessoas de diferentes classes sociais, incluindo crianças e adultos. A diferença consiste no conjunto de conhecimento prévio que o aluno traz consigo (WEISZ et al., 2008).

Neste sentido, Nicolau e Mauro (1986) esclarecem que ao iniciarem a alfabetização, algumas crianças já possuem experiências ricas para serem alfabetizadas quanto ao uso da leitura e escrita. Outras, no entanto, possuem experiências necessárias para atender a outras demandas como, por exemplo, a difícil situação econômica que gera uma experiência dirigida para necessidades do dia a dia, tais como, auxiliar seus pais em tarefas 
domésticas e trabalhos para sustentar a família. Há ainda aquelas que necessitam ser estimuladas com situações que despertem o interesse pela leitura e escrita.

Inclusive, as hipóteses que as crianças formulam sobre a escrita são as mesmas para crianças ricas ou pobres, seus conceitos provêm de ideias simples baseadas na relação entre fala e escrita. Assim, observando, comparando e fazendo relações, a escrita vai se desenvolvendo. Nesse processo, algumas crianças se preocupam mais com a quantidade das letras, outras se preocupam mais com a qualidade das letras, e outras entram em conflito sobre quantas e quais letras podem ser usadas (WEISZ et al., 2008).

O trabalho com a leitura também está condicionado ao desenvolvimento pessoal da criança nos aspectos cognitivo, físico e motor, estes fatores devem ser considerados no processo de alfabetização. Não se pode treinar mecanicamente atividades de forma fragmentada, esquecendo que o aluno necessita ter amplo conhecimento sobre o assunto, atividades devem estar interligadas em um contexto visando promover o desenvolvimento global do aluno (NICOLAU; MAURO, I986).

A alfabetização é um processo contínuo, e a imposição de regras e limites faz com que a escola ignore muitos fatores importantes para o desenvolvimento das crianças. As regras são necessárias, porém, quando utilizadas em excesso, têm como consequência o baixo rendimento dos alunos, comprometendo assim, a qualidade da educação e a aprendizagem deles (NICOLAU; MAURO, I986).

Dohme (20II) corrobora conceituando que um ambiente hostil, pautado pelo medo e coerção faz com que as pessoas se protejam evitando se expor, como consequência, acaba influenciando diretamente na aprendizagem, uma vez que o aluno terá dificuldades para se expressar.

A escola deve, portanto, valorizar as diferenças, o conhecimento $e$ as experiências dos alunos. Deve considerar o repertório sobre o conhecimento de escrita que o aluno possui e assim, desenvolver um contexto de aprendizagem que favoreça o desenvolvimento de todos os alunos. Isso possibilita observar cada criança de forma singular em uma relação de afeto, importante para uma criança que quase não tem contato com textos e seus usos (ROSA, 2003). 


\subsection{A função do professor na relação entre aluno, lúdico e alfabetização.}

Quando inseridas no processo educativo, as atividades lúdicas têm como figura central o professor, cabe a ele a responsabilidade de selecionar os momentos e locais mais oportunos, bem como as atividades mais adequadas e alterá-las conforme as necessidades e o contexto (ROSA, 2003).

Embora as brincadeiras possam surgir de forma natural em diversos momentos da aula, é fundamental que o professor faça um planejamento daquelas que serão necessárias nesse processo (ROSA, 2003). Porém antes de planejar, o professor deve realizar uma observação atenta de sua turma, tais observações revelam dificuldades, superações, necessidades, contribuições, conflitos e asseguram resultados positivos. Muito embora, não seja possível prever possíveis resultados negativos que surgem no percurso (BEMVENUTI, 2006).

Assim, o professor saberá quais são as brincadeiras mais interessantes para as crianças e quais delas possuem mais importância no processo educativo. E ao disponibilizar as brincadeiras, os professores já devem ter calculado o tempo necessário, espaços apropriados para cada tipo e materiais adequados para cada uma delas (ROSA, 2003).

Rosa (2003) salienta que é importante examinar o potencial pedagógico de cada brincadeira e procurar recursos que estimulem as crianças a procurarem mais informações sobre o tema com diversos meios (livros, filmes, fotos etc.). Devem pesquisar sobre a melhor estratégia que poderá utilizar para estimular o interesse das crianças pela brincadeira e para atingir seus objetivos.

Entre as diversas estratégias, uma delas é a utilização dos jogos e brincadeiras que fazem parte da vida deles, isso faz com que o aluno se identifique no grupo, escola e cidade. Ao valorizar o aluno e seu convívio social, o professor conseguirá que o aluno participe ativamente e de forma espontânea, evitando assim, resultados semelhantes e previstos (BEMVENUTI, 2006).

Para Dohme (20II), a motivação também deve ser considerada como fundamental, a criança está sempre predisposta ao movimento, à fantasia e à espontaneidade, com isso as atividades lúdicas afloram sua motivação e permitem que elas aceitem as regras do jogo de forma natural. $\mathrm{O}$ professor deve considerar essa capacidade 
espontânea para adotar uma estratégia lógica e coerente, que proporcione o desenvolvimento da criança.

É importante observar que diversos fatores podem influenciar as crianças durante as brincadeiras. Assim, Sponseller (1982, apud ROSA, p.5I), fez uma relação dos fatores que afetam as brincadeiras das crianças.

I. Os fatores físicos do espaço afetam a brincadeira social, a aprendizagem dos papéis sexuais e o nível e a qualidade da atividade.

2. A interação da criança com seus pais afeta sua capacidade de brincar.

3. A interação da criança com seus pares influencia a brincadeira social, a aprendizagem dos papéis sexuais e o nível e a qualidade da atividade, e auxilia no processo de descentralização.

4. A facilitação direta ou indireta do brincar por parte do professor afeta o tipo, a quantidade e a qualidade da brincadeira. Ela sinaliza a adequação ou inadequação da brincadeira na escola.

5. O treinamento ou a experiência em certos tipos de brinquedo pode afetar o comportamento na sala de aula, e pode melhorar a aprendizagem de habilidades acadêmicas, especialmente, aquelas que requerem processos cognitivos superiores.

Quanto às limitações, elas devem ser analisadas e compreendidas para adotar a melhor estratégia, a fim de serem superadas, minimizadas ou substituídas. O professor deve entender que cada criança tem diferentes habilidades e diferentes capacidades cognitiva, afetiva e corporal. Também deve considerar que cada criança atua conforme suas habilidades e que não existe habilidades ou capacidades melhores ou piores e sim diferentes. Atividades lúdicas por si só possibilitam que as crianças desenvolvam as mais diversas habilidades, independentemente de suas aptidões, e cada criança encontra aquela que melhor se adapta aos seus atributos. (DOHME, 20II) 


\section{CONSIDERAÇÕES FINAIS}

O presente trabalho investigou os benefícios do lúdico no processo de alfabetização nos anos iniciais do ensino fundamental. Constatou-se que ele contribui de forma significativa na aquisição da leitura e escrita, que se desenvolvem simultaneamente com as capacidades física, afetiva, emocional, cognitiva e social, incluindo a sensação de prazer e satisfação que ele suscita nas crianças.

A questão aqui investigada, teve origem a partir das indagações feitas pelas autoras nos diversos estágios curriculares em escolas, onde se constatou a grande necessidade de professores se informarem acerca do conhecimento prévio dos alunos com relação à linguagem e escrita, de sua vida sociocultural, bem como acerca da situação que o aluno apresenta quanto ao desenvolvimento emocional, e também como se desenvolve o conhecimento e demais habilidades relacionadas ao processo de alfabetização. Inclui-se ainda a importância de saber como a criança se relaciona com o lúdico, para adotar a melhor estratégia de aprendizagem considerando essas necessidades.

Sendo assim, entendeu-se necessário pesquisar trabalhos que esclarecem sobre o desenvolvimento pessoal e cerebral da criança, bem como a importância do afeto e emoção para o processo de alfabetização e para o desenvolvimento global do aluno.

As fontes bibliográficas selecionadas para o estudo indicam que a falta desses conhecimentos dificulta o processo de alfabetização, o desenvolvimento do aluno e impedem uma relação de proximidade e afeto entre professor e aluno, inviabilizando o sucesso das estratégias lúdicas.

Reiterou-se a aprendizagem significativa por verificar que ela constitui importante mediação entre lúdico e alfabetização, assim como, valoriza as experiências prévias, o contexto social e os processos de desenvolvimento (cognitivo, afetivo e psicomotor). Por meio dela, situa-se a alfabetização realizada com atividades de reflexão sobre a escrita aliada à atividades que fazem sentido na vida do aluno. Nessa proposta de ensino, o professor se torna um aliado assegurando meios para desenvolver a leitura e escrita e se ajustando às necessidades do aluno.

Conclui-se que os benefícios do lúdico no processo de alfabetização são numerosos e valiosos, cabendo ao professor se atualizar e adaptar suas estratégias às 
capacidades do aluno, às propostas atuais de ensino e às atividades lúdicas. Um professor consciente e bem informado sempre saberá conciliar o conteúdo da disciplina à diferentes situações, priorizando as necessidades e capacidades do seu aluno.

É importante destacar a necessidade de realizar outras pesquisas para o contexto de alfabetização nesta temática. Novas pesquisas poderão sugerir estratégias fundamentais para o aperfeiçoamento das práticas lúdicas no processo de alfabetização, em especial, se atentando para o desenvolvimento global do aluno, e promovendo o autoconhecimento e a sociabilização da criança com o meio.

\section{AGRADECIMENTOS}

Agradecemos a Deus, por nos dar forças, coragem e perseverança, a fim de nunca desistir dos nossos objetivos e seguir em frente com esse estudo.

Agradecemos ao Centro Universitário São Camilo, seu corpo docente, direção e administração pelo suporte e ajuda durante os anos de graduação e por terem transmitido seu saber com muito profissionalismo.

A orientadora deste trabalho, Professora Dra. Claudia Lopes da Silva, pelo suporte que nos possibilitou construí-lo no pouco tempo que lhe coube pelas correções e orientações.

Ao tutor presencial professor Tassio Jose da Silva, pelos ensinamentos, correções e dedicação. Além do conteúdo programado, nos transmitiu também o sentido da amizade e do respeito.

A coordenadora do nosso polo Deborah Regina Freitas Dantas pela dedicação, atenção, paciência e preocupação em nos manter sempre informados acerca das novidades e cronogramas.

A todos os alunos da turma de Pedagogia de 2020, pela amizade, apoio e palavras de incentivo que proporcionaram um ambiente alegre e amigável.

Agradecemos ainda aos familiares, que ao longo desta etapa nos apoiaram e nos incentivaram, atitudes que serviram de alicerce para as nossas realizações.

Agradecemos profundamente a muitas pessoas que direta ou indiretamente fizeram parte da nossa formação.

"Faz-se necessário ampliar o conceito de escrita [...] resgatando o direito da criança a uma educação que respeite seu processo de construção do pensamento, que lhe permita desenvolver-se nas linguagens expressivas do jogo, do desenho e da música como 
instrumentos simbólicos de leitura e escrita de mundo, promovendo o desenvolvimento cognitivo e afetivo-social da criança".

(ROSA, 2003, p.39)

\section{REFERÊNCIAS}

BARROSO, Cleonice Alves Pereira; OLIVEIRA, Joelma Adileu Pereira de; OLIVEIRA, Maria Jose de; SHIROIWA, Suzi Satico; SILVA, Leia Regina Thome da. O lúdico no processo de alfabetização: possibilidades para o desenvolvimento global da criança. 2020. $37 \mathrm{f}$. Trabalho de conclusão de Curso (Licenciatura em Pedagogia) - Centro Universitário São Camilo, 2020.

BEMVENUTI, Alice. O lúdico na prática pedagógica. [s.1.]: ABDR; IBPEX, 2006. 218p.

BIBLIOTECA VIRTUAL DOS DIREITOS HUMANOS. Declaração dos Direitos da Criança (1959). Biblioteca Virtual dos Direitos Humanos. Disponível em:

〈http://www.direitoshumanos.usp.br/index.php/Crian\% $\mathrm{C}_{3 \%} \% \mathrm{~A}_{7 \mathrm{a}} /$ declaracao-dosdireitos-da-crianca.html >. Acesso em: 20 jan. 2020.

BRASIL. Base Nacional Comum Curricular. Brasília (DF): Ministério da Educação, 2017. Disponível em: <http://basenacionalcomum.mec.gov.br//cne/arquivos/pdf/ rcebo3_99.pdf $>$. Acesso em 20 jan. 2020.

Constituição da República Federativa do Brasil de 1988. Presidência da República - Casa Civil. Disponível em: 〈http://www.planalto.gov.br/ccivil_03/constituicao/constituicao.htm〉. Acesso em: I9 fev. 2020 .

. Lei no 8.069, de 13 de julho de 1990. Dispõe sobre o Estatuto da Criança e do Adolescente e dá outras providências. Presidência da República - Casa Civil. Disponível em: 〈http://www.planalto.gov.br/ccivil_03/leis/18o69.htm>. Acesso em: 22 fev. 2020.

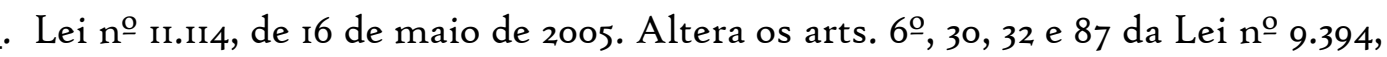
de 20 de dezembro de 1996, com o objetivo de tornar obrigatório o início do ensino fundamental aos seis anos de idade. Presidência da República - Casa Civil. Disponível em: 〈http://www.planalto.gov.br/ccivilo3/Ato2004-2006/2005/Lei/LinI4.htm〉. Acesso em: 22 jan.2020. 
Lei $n^{\circ}$ II.274, de fevereiro de 2006. Altera a redação dos arts. 29, 30, 32 e 87 da Lei no 9.394, de 20 de dezembro de 1996, que estabelece as diretrizes e bases da educação nacional, dispondo sobre a duração de 9 (nove) anos para o ensino fundamental, com matrícula obrigatória a partir dos 6 (seis) anos de idade. Presidência da República - Casa Civil. Disponível em: <http://www.planalto.gov.br/ccivil_03/_ato20042006/2006/lei/lir274.htm>. Acesso em: 20 fev. 2020.

Projeto de lei n. 5.609-a/2013. Altera a Lei no 12.801, de 24 de abril de 2013, para dispor sobre a reestruturação do Ensino Fundamental de 9 anos, para garantir à criança, a partir dos 6 (seis) anos de idade, a aquisição da alfabetização/letramento na perspectiva da ludicidade e do seu desenvolvimento global; tendo parecer da Comissão de Educação, pela rejeição. Câmara dos deputados. Disponível em: 〈https://www.camara.leg.br/proposicoesWeb/prop_mostrarintegra?codteor $=1247869$ >. Acesso em: 20 fev. 2020.

. Instituto Nacional de Estudos e Pesquisas Educacionais Anísio Teixeira. Plano Nacional de Educação PNE 2014-2024: Linha de Base. Brasília: Inep, 2015. Disponível em: $\langle$ http://portal.inep.gov.br/documents/r86968/485745/Plano+Nacional+de+Educa\% $\% 3 \% \mathrm{~A}$ $7 \% \mathrm{C}_{3} \% \mathrm{~A}_{30}+\mathrm{PNE}+2014-2024++\mathrm{Linha}+\mathrm{de}+\mathrm{Base} / \mathrm{c} 2 \mathrm{ddofaa}-7227-40 e e-\mathrm{a} 20-$ I2c6fc7770of?version=I.I >. Acesso em: i9 fev. 2020.

CENTRO DE ESTUDOS EM ALFABETIZAÇÃO E LINGUAGEM. Manual didático Jogos de Alfabetização. Recife (PE): MEC; UFPE/CEEL, 2009. 8op.

CONSENZA, Ramon M.; GUERRA, Leonor B. Neurociência e Educação: como o cérebro aprende. Porto Alegre: Artmed, 20II. I5Ip.

KISHIMOTO, Tizuco M.(Org.) Jogo, Brinquedo, Brincadeira e a Educação. O jogo e a educação infantil. São Paulo: Cortez, 2003. 43p.

Jogos infantis: o jogo, a criança e a educação. Io. ed. Petrópolis, RJ: Vozes, 1993.

$128 \mathrm{p}$. 
O jogo e a educação infantil. São Paulo: Pioneira, 1994.

LYRA, Pompeia V, et al. Entendendo o desenvolvimento infantil: contribuições das neurociências e o papel das relações afetivas para pais e educadores. Recife: UFRPE, 2017. 5op.

NICOLAU, Marieta L. M.; MAURO, Maria A. F. Alfabetizando com sucesso. São Paulo. E.P.U, 1986. II4p.

PANTANO, Telma.; ROCCA, Cristina C. A. Como se estuda? Como se aprende? Um guia para pais, professores e alunos, considerando os princípios das neurociências. São José dos Campos, SP: Pulso, 2015. 320p.

ROSA, Adriana. Lúdico \& Alfabetização. Curitiba (Paraná): Juruá, 2003. I20p.

WEISZ, Telma, et al. Alfabetização no Contexto das Políticas Públicas. Simpósio 15. Disponível em< http://portal.mec.gov.br/seb/arquivos/pdf/volid.pdf- Portal do MEC>. Acesso em: 28 fev. 2020 